\title{
Diagnóstico laboratorial da acromegalia
}

Laboratory diagnosis of acromegaly

Pedro Weslley Rosário'
$\mathrm{R}$ ecentemente, foram apresentadas as recomendações do Departamento de Neuroendocrinologia da Sociedade Brasileira de Endocrinologia e Metabologia (SBEM) para o diagnóstico e tratamento da acromegalia no Brasil (1). Os comentários a seguir visam contribuir especificamente em relação ao diagnóstico laboratorial.

Embora nas recomendações seja ressaltado que "não existe uma faixa de normalidade para o GH basal que diferencie indivíduos normais daqueles com acromegalia", reconhece-se que, em pacientes com IGF-1 indubitavelmente elevado, o valor do GH basal pode definir o diagnóstico, dispensando o teste de supressão com sobrecarga oral de glicose [Quadro l (1)]. Conclui-se, portanto, que existe um valor de GH basal acima do qual, combinado com IGF-1 indubitavelmente alto, seja possível identificar pacientes acromegálicos. Com base nos resultados do GH basal (Immulite) obtidos em adultos saudáveis, os limites de $5 \mu \mathrm{g} / \mathrm{L}$ para homens e $10 \mu \mathrm{g} / \mathrm{L}$ para mulheres parecem razoáveis, pois valores acima desses raramente são vistos em indivíduos normais, especialmente pela manhã, quando picos de secreção de GH em adultos são excepcionais (2). Em relação ao IGF-1 sérico, tivemos a oportunidade de analisar adultos (exceto gestantes) que exibiam níveis persistentemente acima do limite superior da normalidade (LSN) para idade, mas sem acromegalia e com adequada supressão do GH. Foram 25 indivíduos saudáveis $(3), 50$ pacientes com diabetes ou intolerância à glicose (4) e 15 com hipertireoidismo não tratado (informação não publicada), com valores repetidamente elevados de IGF-1 na ausência de acromegalia (falso-positivo). Em todos, exceto dois, os valores de IGF-1 foram abaixo de 1,5 vez o LSN. Assim, como forma de melhor definir o que nas recomendações é chamado de valores "indubitavelmente" elevados (1), os limites de $5 \mu \mathrm{g} / \mathrm{L}$ em homens e $10 \mu \mathrm{g} / \mathrm{L}$ em mulheres para o GH basal e 1,5 vez o LSN para o IGF-1 sérico em adultos (exceto gestantes) são interessantes. A combinação de valores acima desses limites estabeleceria o diagnóstico de acromegalia, sem necessidade da supressão com glicose oral.

Pelas recomendações ( 1 ), pacientes com GH basal > 0,4 $\mu \mathrm{g} / \mathrm{L}$ e/ou IGF-1 elevado, exceto se ambos indubitavelmente alterados, devem ser submetidos ao teste de supressão [Figura l (1)]. Considerando que o objetivo do teste é suprimir o GH e não explorar a resposta paradoxal eventualmente presente em alguns casos de acromegalia, é difícil justificá-lo quando o nível de GH em condições basais já se encontra inferior ao que se espera após supressão. Se o objetivo do teste é suprimir o $\mathrm{GH}$ para $<0,4$ $\mu \mathrm{g} / \mathrm{L}$, é pouco razoável realizá-lo em pacientes que já apresentam $\mathrm{GH}<0,4 \mu \mathrm{g} / \mathrm{L}$ em condições basais. Assim, ainda que acromegalia seja possível em pacientes com IGF-1 elevado e $\mathrm{GH}$ basal $<0,4 \mu \mathrm{g} / \mathrm{L}$, não seria o teste de supressão auxiliar nessa definição.

Outro aspecto que merece reflexão é a recomendação de que pacientes com $\mathrm{GH}$ basal $>0,4 \mu \mathrm{g} / \mathrm{L}$, a despeito do IGF-1 normal, sejam submetidos à supressão do GH (1).
${ }^{1}$ Instituto de Ensino e Pesquisa da Santa Casa de Belo Horizonte; Departamento de Neuroendocrinologia, Serviço de Endocrinologia, Santa Casa de Belo Horizonte, Belo Horizonte, MG, Brasil

Correspondência para: Pedro Weslley Rosário Centro de Estudos e Pesquisa da Clínica de Endocrinologia e Metabologia (CEPCEM) Av. Francisco Sales, 1.111, $5^{\circ} \mathrm{D}$ 30150-221 - Belo Horizonte, MG, Brasil

pedrorosario@globo.com

Recebido em 19/Abr/2011 Aceito em 4/Set/2011 
Com essa recomendação, o teste será necessário na maioria dos casos. Valores de $\mathrm{GH}$ basal $>0,4 \mu \mathrm{g} / \mathrm{L}$, com o ensaio mais amplamente usado no Brasil (Immulite), foram encontrados em aproximadamente $55 \%$ dos homens e $85 \%$ das mulheres em 1.200 indivíduos saudáveis (2), e condições que sabidamente podem elevar o GH haviam sido excluídas em todos eles. A dosagem do IGF-1 sérico é altamente sensível para o diagnóstico de acromegalia, tanto que nas recomendações ressalva-se que acromegalia é possível mesmo com nadir do $\mathrm{GH}<0,4 \mu \mathrm{g} / \mathrm{L}$, mas mesmo esses pacientes apresentariam IGF- 1 elevado ( 1 ). Além disso, as condições que causam redução do IGF-1 e poderiam mascarar o diagnóstico laboratorial são conhecidas $(1,3)$. De maneira geral, o encontro de IGF-1 normal para idade, desde que na ausência dessas condições interferentes, seria suficiente para exclusão da acromegalia. Com isso, evitar-se-ia que muitos pacientes (aqueles com IGF-1 normal e $\mathrm{GH}$ basal > 0,4 $\mu \mathrm{g} / \mathrm{L}$ ) fossem submetidos ao teste de supressão, sem comprometimento da detecção da doença.

Também pelas recomendações (1), na suspeita de acromegalia, o achado de IGF-1 normal e GH basal $>0,4 \mu \mathrm{g} / \mathrm{L}$, além de ser indicação do teste de supressão, se neste o $\mathrm{GH}$ permanece $>0,4 \mu \mathrm{g} / \mathrm{L}$, tem-se o diagnóstico confirmado (1). Em mulheres saudáveis, sem qualquer das condições que conhecidamente podem alterar a supressão do $\mathrm{GH}$, um nadir do $\mathrm{GH}>0,4$ $\mu \mathrm{g} / \mathrm{L}$ pelo ensaio Immulite foi visto em $25 \%$, sendo ainda maior nas mulheres jovens (5). A preocupação é que em mulheres esse critério diagnóstico (nadir GH > $0,4 \mu \mathrm{g} / \mathrm{L}$ mesmo com IGF-1 normal) resulte em alta taxa de falso-positivo e, como consequência, realização indevida de métodos de imagem, com maior problema ainda se considerarmos que incidentaloma hipofisário na ressonância magnética não é incomum em adultos. É claro que o valor preditivo positivo (VPP) do nadir do GH é modificado pela suspeita clínica. Porém, as recomendações (1) não especificam quantos dos vários sinais ou sintomas enumerados na tabela 1 indicariam a necessidade de investigação laboratorial, se apenas um, se dois ou mais etc. (1). Certamente pelo menos um daqueles está presente em grande parte da população feminina adulta, especialmente alguns inespecíficos e prevalentes (como artralgia, hipertensão arterial, diabetes, alteração do humor e depressão, bócio, fraqueza, fadiga e letargia). A recomendação geral de interromper a investigação laboratorial diante do IGF-1 normal, desde que na ausência de fatores interferentes (que causam redução desse hormônio), também preveniria esses falsos diagnósticos laboratoriais de acromegalia em mulheres saudáveis com sinais e/ou sintomas inespecíficos.

Alternativamente, a adoção de valores de corte distintos para o nadir do $\mathrm{GH}$ após supressão com glicose oral, em vez de um cut off único, levando-se em consideração sexo, idade e IMC, além do ensaio $(5,6)$, certamente reduziria o número de casos de acromegalia com IGF-1 elevado com supressão do GH considerada normal e aumentaria o VPP do nadir do GH alterado.

Ressalta-se a relevância das considerações anteriores, pois, para alcançarmos o objetivo do diagnóstico mais precoce da acromegalia (1), obrigatoriamente maior número de indivíduos deverão ter a doença suspeitada e ser investigados laboratorialmente, o que tende a reduzir o VPP dos testes laboratoriais (4), quando comparado à investigação restrita a pacientes com alta suspeita para acromegalia $(7,8)$.

Declaração: os autores declaram não haver conflitos de interesse científico neste estudo.

\section{REFERÊNCIAS}

1. Vieira Neto L, Abucham J, Araújo LA, Boguszewski CL, Bronstein MD, Czepielewski M, et al. Recomendações do Departamento de Neuroendocrinologia da Sociedade Brasileira de Endocrinologia e Metabologia para o diagnóstico e tratamento da acromegalia no Brasil. Arq Bras Endocrinol Metab. 2011;55:91-105.

2. Rosario PW. Measurement of basal GH in the diagnosis of acromegaly. Arq Bras Endocrinol Metabol. 2010;54:668-9.

3. Rosario PW. Normal values of serum IGF-1 in adults: results from a Brazilian population. Arq Bras Endocrinol Metabol. 2010;54:477-81.

4. Rosario PW. Frequency of acromegaly in adults with diabetes or glucose intolerance and estimated prevalence in the general population. Pituitary. 2011;14(3):217-21.

5. Rosario PW, Furtado MS. Growth hormone after oral glucose overload: revision of reference values in normal subjects. Arq Bras Endocrinol Metabol. 2008;52:1139-44.

6. Rosario PW, Salles DS, Bessa B, Furtado MS. Nadir growth hormone after oral glucose overload in obese subjects. Arq Bras Endocrinol Metabol. 2010;54:507-9.

7. Rosario PW, Calsolari MR. Screening for acromegaly by application of a simple questionnaire evaluating the enlargement of extremities in adult patients seen at primary health care units. Pituitary 2011 (in press).

8. Rosario PW, Purisch S. Biochemical acromegaly in patients with prolactinoma during treatment with dopaminergic agonists. Arq Bras Endocrinol Metabol. 2010;54:546-9. 